\title{
Respiratory effects of air pollution in chronic obstructive pulmonary disease: a three month prospective study
}

\author{
Elisabeth S M Harré, Phillip D Price, Robert B Ayrey, Leslie J Toop, Isobel R Martin, \\ G Ian Town
}

\begin{abstract}
Background - A study was undertaken to investigate the relationship between air pollution levels and respiratory symptoms and peak expiratory flow rate (PEFR) in subjects with chronic obstructive pulmonary disease (COPD) living in Christchurch, New Zealand.

Methods - Forty subjects aged over 55 years with COPD completed twice daily diaries for three months during the winter of 1994. Subjects recorded respiratory symptoms, PEFR, outdoor activity, visits to doctor or hospital, and medication use. All were resident within a $5 \mathrm{~km}$ radius of the regional council's air pollution monitoring site. Daily and hourly mean pollutant levels (particulates $\left(\mathbf{P} \mathbf{M}_{10}\right)$, nitrogen dioxide $\left(\mathrm{NO}_{2}\right)$, sulphur dioxide $\left(\mathrm{SO}_{2}\right)$ and carbon monoxide (CO)) were measured at the monitoring site.
\end{abstract}

Results - Pollution levels were generally low relative to those recorded in previous years. The New Zealand Ministry for the Environment guidelines for $\mathbf{P} \mathbf{M}_{10}$ were exceeded on five occasions, and for $\mathrm{CO}$ six times. No association was found between PEFR and any of the pollution variables. $A$ rise in $\mathbf{P M} \mathbf{M}_{10}$ concentration equivalent to the interquartile range was associated with an increase in night time chest symptoms (relative risk $1.38,95 \%$ CI 1.07 to 1.78 ). A rise in $\mathrm{NO}_{2}$ concentrations equivalent to the interquartile range was associated with increased reliever inhaler use (relative risk $1.42,95 \%$ CI 1.13 to 1.79 ) and for 24 hour lag analysis with increased nebuliser use (relative risk $2.81,95 \%$ CI 1.81 to 4.39 ). There was no increase in the relative risk of other symptoms in relation to pollution levels.

Conclusions - These effects, demonstrated in a small susceptible group of subjects with COPD, indicate that adverse outcomes can be measured in response to pollution levels that are within current guidelines.

(Thorax 1997;52:1040-1044)

Keywords: chronic obstructive pulmonary disease, air pollution, particulates, nitrogen dioxide, carbon monoxide.

Christchurch is a coastal city of 307000 people situated on the Canterbury Plains of New Zealand with hillside suburbs to the south. This topography acts to inhibit the dispersion of air pollutants and, when combined with temperature inversion during the autumn and winter months, traps polluted air over the greater urban area. The primary sources of air pollution include domestic fires (both coal and wood) and motor vehicles. Winter concentrations of particulate pollution and carbon monoxide (CO) regularly exceed World Health Organisation (WHO) and draft New Zealand Ministry for the Environment guidelines. ${ }^{1}$ WHO guideline standards for $\mathrm{PM}_{10}$ (airborne particulate matter $<10 \mu \mathrm{m}$ in diameter) were exceeded up to nine times annually during the period 1988-1992. Guidelines for CO were exceeded 15 times in 1992 with levels up to twice the WHO eight hour standard being recorded. ${ }^{1}$

Since the WHO guidelines for these pollutants were set at levels designed to protect human health, the regular occurrence of levels which exceed these guidelines is of concern. Moreover, recent studies from areas where pollution levels rarely exceed guidelines have reported associations between air pollution and health outcomes such as mortality and morbidity, including respiratory symptoms..$^{2-8}$

Those with underlying respiratory disease are likely to be more susceptible to the adverse effects of air pollution. Higgins et $a l^{9}$ investigated the effects of air pollution on peak expiratory flow rate (PEFR) and respiratory symptoms in people with asthma and chronic obstructive pulmonary disease (COPD). While pollution levels did not exceed WHO guidelines during the study period, they noted significant increases in PEFR variability, bronchodilator use, and respiratory symptoms with higher sulphur dioxide $\left(\mathrm{SO}_{2}\right)$ and ozone $\left(\mathrm{O}_{3}\right)$ concentrations.

Our hypothesis was that air pollution may cause an increase in respiratory symptoms in a susceptible population. The specific objective was to establish whether air pollution levels currently observed in Christchurch during the winter months have any significant effects on pulmonary function, symptoms, and medication use in subjects with COPD.

\section{Methods}

This study was implemented by the Canterbury Respiratory Research Group in collaboration with the Department of Public Health and General Practice, and the Canterbury Regional Council (CRC). 
Potential subjects were recruited from three sources: (1) general practitioners in the central Christchurch area $(n=25)$; (2) a communitybased COPD support group $(n=28)$; and (3) newspaper advertisements $(n=8)$. These 61 subjects were screened in their homes by a research nurse to determine their suitability for the study. A respiratory health questionnaire which included demographic data, medication use, medical history, and smoking history was administered and spirometric tests (Vitalograph Alpha) were performed. For inclusion in the study subjects had to meet the American Thoracic Society criteria for COPD,${ }^{10}$ be aged over 55 years, have a forced expiratory volume in one second $\left(\mathrm{FEV}_{1}\right)$ of $<70 \%$ predicted, be ambulant and resident within $5 \mathrm{~km}$ of the council monitoring station. Current smokers were excluded.

Written informed consent was obtained from those who met the inclusion criteria and who were willing to participate in the study. The study was approved by the Southern Regional Health Authority ethics committee (Canterbury). The duration of the study was three months, from June to the end of August 1994.

DATA RECORDING

Subjects were each provided with a low reading mini-Wright peak flow meter and a study diary. They were instructed to record twice daily details of respiratory symptoms (cough, wheeze, chest tightness, shortness of breath, change in sputum volume), nose, throat or eye irritation, PEFR, medication use, and visits to the doctor. Participants were requested to omit recordings if travelling away from Christchurch for 24 hours or longer. Home visits and checks by telephone were conducted at intervals throughout the study. Study diaries and peak flow techniques were reviewed and further training was given where necessary to ensure completeness of data collection.

In Christchurch the New Zealand Ministry of Health subcontracts environmental monitoring to the Institute of Environmental Science and Research (Environmental). Meteorological data (wind speed, temperature) were obtained using a Climatronics (USA) system. Air pollution data included $\mathrm{PM}_{10}$ (Environnement SA MPSI 100, France) (May, June and July), Rupprecht and Patashnick TEOM 1400, USA (August and September), CO (Hartman and Braun Uras 3G, Germany), $\mathrm{SO}_{2}$ (Environment SA AF 20M, France), and $\mathrm{NO}_{2}$ (Environment SA AC 30M).

STATISTICAL ANALYSIS

The objectives of the analysis were (1) to model the daily probability of worsening of symptoms in the cohort as functions of daily pollution levels and climatic variation, and (2) to model the variation in PEFR as a function of daily pollution levels and climatic variation.

To satisfy both objectives stepwise (backward elimination) models were fitted using the pollution/climatic variables as predictors. PEFR (being a continuous variable) was modelled using a log-linear regression model and the categorical symptom variables were modelled using Poisson regression models. The details of the two models are presented below.

Modelling of symptom variables (chest symptoms, wheeze, inhaler and nebuliser use, eye irritation) Symptom variables were converted to binary (yes/no) indicator variables which indicated significant worsening of each symptom over the previous day. A symptom "incident" was defined as having occurred if the symptom reading was greater than two sample standard deviations above the mean level for that symptom for that patient (the symptom readings were ordinal categorical scores). Defining $\mathrm{P}_{i}$ to be the probability that a symptom incident (for one type of symptom) occurred on the $i$ th day of the study, then a regression model for $\mathrm{P}_{i}$ for each symptom using the pollution/climatic variables as predictors would demonstrate any significant relationship between air pollution and deteriorating respiratory status. Poisson regression was considered to be the most appropriate model for this situation since it provides direct estimates of the relative risks of symptom incidents being related to the pollution predictor variables.

The Poisson regression model has the general form

$$
\ln \left(\mathbf{P}_{i}\right)=\beta_{0}+\beta_{1} \mathrm{X}_{1 i}+\beta_{2} \mathrm{X}_{2 i}+\ldots+\beta_{\mathrm{L}} \mathrm{X}_{\mathrm{L} i}
$$

where $\mathrm{X}_{j i}(j=1,2 \ldots, \mathrm{L})$ is the value of predictor variable $j$ on day $I$ of the study. Since $\mathrm{P}_{j 1} / \mathrm{P}_{j 2}$ is the relative risk of a symptom incident at two covariate settings (values of the predictors), then $\exp \left(\beta_{j}\right)$ is the relative risk for the predictor $j$.

There were three main assumptions required for this model to be appropriate. Firstly, it is clearly necessary for the fitted estimate of $\mathrm{P}_{i}$ to be less than 1 . The model estimates of $\ln$ $\left(\mathbf{P}_{i}\right)$ are not constrained, however, since the estimates of the $\beta_{j}$ are maximum likelihood estimates (MLEs). The probability of an estimate of $\mathrm{P}_{i}$ being greater than 1 was thought to be asymptotically negligible and did not, in fact, occur with any model fitted. Secondly, as with most regression models it is necessary for the dependent variable values (the $\mathbf{P}_{i}$ ) to be independent. In their initial form the symptom variables contained serial autocorrelation as would be expected since patients' symptom levels on successive days are highly correlated. However, the binary indicator variables which indicated the occurrence of symptom events removed most of this autocorrelation. Thus, the values of $\mathrm{P}_{i}$ (the probability of the indicator variables denoting a symptom incident on day $I$ ) could be assumed to be independent. Examination of the residual autocorrelation in the Poisson regression models found this assumption to be justified, with the largest residual autocorrelation value being 0.31 and the values being much smaller than this for most models fitted.

The third assumption (which applies to Poisson regression models in general) is that $\mathrm{P}_{i}$ is Poisson distributed. Violation of this assumption does not affect the estimates of the 
Table 1 Demographic data $(n=40)$

\begin{tabular}{lll}
\hline Mean age (years) & 72 & (range 55-83) \\
Female/male* $_{\text {Mean FEV }}^{*}(1)$ & $16 / 24$ & \\
Mean FEV 1 (\% predicted) & 1.01 & (range 0.33-1.83) \\
Prescribed a bronchodilator (\%) & 41 & (range 17-66) \\
Prescribed an inhaled corticosteroid (\%) & 85 & \\
Taking prednisone during the study (\%) & 88 & \\
\hline
\end{tabular}

$\mathrm{FEV}_{1}=$ forced expiratory volume in one second.

* Subjects recruited from GPs included a larger number of men and mean $\mathrm{FEV}_{1}$ was lower than for remaining subjects. regression coefficients $\beta_{j}$ since they are MLEs. However, it does affect the estimates of the covariance matrix for the $\beta_{j}$ values. To ensure that the estimated covariance matrix was accurate, a model robust method was used to estimate it $^{1112}$ which means that both the $\beta_{j}$ values and their covariance matrix were unbiased estimates even if the Poisson assumption was violated.

The same Poisson regression model described above was fitted to every symptom indicator variable. All the pollution and climatic variables were considered for inclusion as predictors, as were the day of the study of that observation $(I)$ and the day of the week of that date to allow for any linear drift or weekly patterns in the symptoms. Preliminary ANOVA investigations indicated that there was a possibly significant 24 hour lag effect of some of the pollution variables on symptom incidents, so previous days' pollution readings were also included as predictors. Interaction terms were found to be non-significant. Using stepwise backward elimination non-significant predictors were removed to obtain the most accurate estimates of the regression coefficients for the main pollutants $\left(\mathrm{CO}, \mathrm{NO}_{2}, \mathrm{PM}_{10}, \mathrm{SO}_{2}\right)$.

Since $\mathrm{P}_{i}$ was the probability of symptom events occurring in the entire cohort on day $I$ of the study, it was possible that heterogeneity between the patients could affect the results of fitting the regression models (since different patients might have different responses to certain pollution/climatic conditions. The cohort was therefore stratified into groups (strata) which showed homogeneous symptomatic behaviour over the study period. The stratification variables used were identified from preliminary ANOVA analysis. The best stratification criteria (which explained most of the heterogeneity in the cohort) was found to be the recruitment source (GP, support group, or newspaper). The Poisson regression models were hence fitted for each stratum separately. Because of the homogeneity within the strata, the variance of the estimates of the $\beta_{j}$ values would then be reduced. Pooled estimates of the variances of the overall values of $\beta_{j}$ were calculated using the variance weighted sums of the strata $\beta_{j}$ values. This allowed more accurate calculation of the overall RR estimates for the pollution variables.

\section{Modelling of PEFR}

The variation in morning and evening PEFR was modelled using two log-linear regression models incorporating adjustment for first order autocorrelation. These models were of the form:

$$
\ln (\mathrm{PEFR})=\beta_{0} / \beta_{1} \mathrm{X}_{1 i}=\beta_{2} \mathrm{X}_{2 i}+\ldots+\beta_{L} \mathrm{X}_{L \mathrm{i}}
$$

If a pollution/climatic predictor $\left(\mathrm{X}_{i j}\right)$ was found to be significant then it indicated that a change in the level of that predictor was associated with a change in PEFR. The same stepwise approach and set of predictors (including lagged predictors) were used as for the symptom models. It was not considered necessary to stratify the cohort before fitting the models for PEFR.

The models were estimated to have power greater than $95 \%$ to detect a $10 \%$ change in mean PEFR with a sample size of 40 .

\section{Results}

Forty three of the 61 subjects screened were included in the study and 40 completed it, of whom 13 were recruited from general practitioners, 19 from newspaper advertising, and eight from a local COPD support group. Baseline demographic data, medication use, and lung function are presented in table 1 . All but two subjects were previous smokers. The study group was heterogeneous in baseline medical characteristics with those recruited by GPs having a lower baseline $\mathrm{FEV}_{1}$. The response patterns were consistent for most outcome variables, although the magnitudes varied so group data only are presented here.

AIR POLLUTION LEVELS

Summary data for the pollution variables during the study period are shown in figs 1 and 2 . While concentrations were generally below
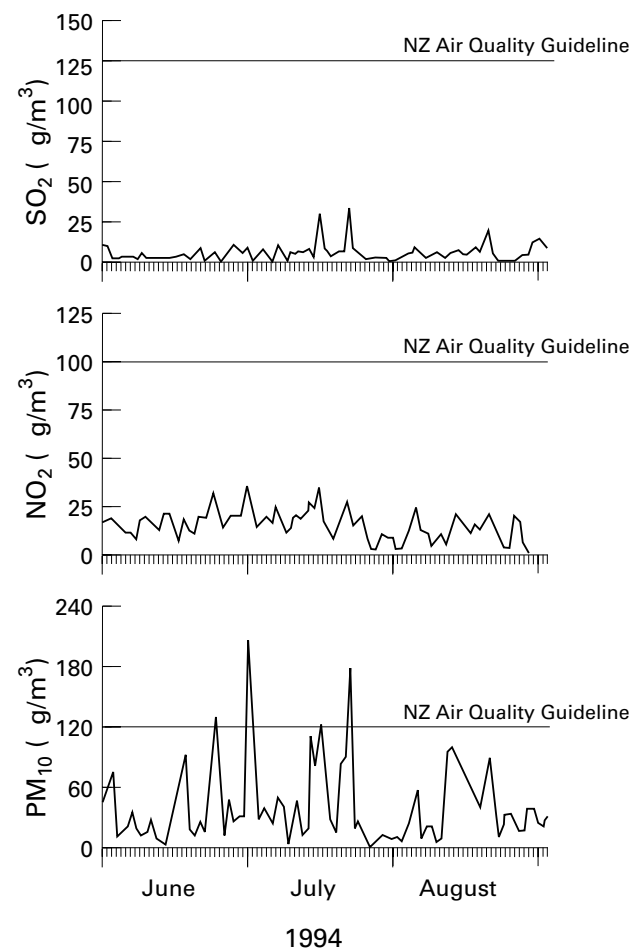

Figure 1 Mean daily data for sulphur dioxide $\left(\mathrm{SO}_{2}\right)$, nitrogen dioxide $\left(\mathrm{NO}_{2}\right)$, and particulate matter $\left(\mathrm{PM}_{10}\right)$ during the study period. 

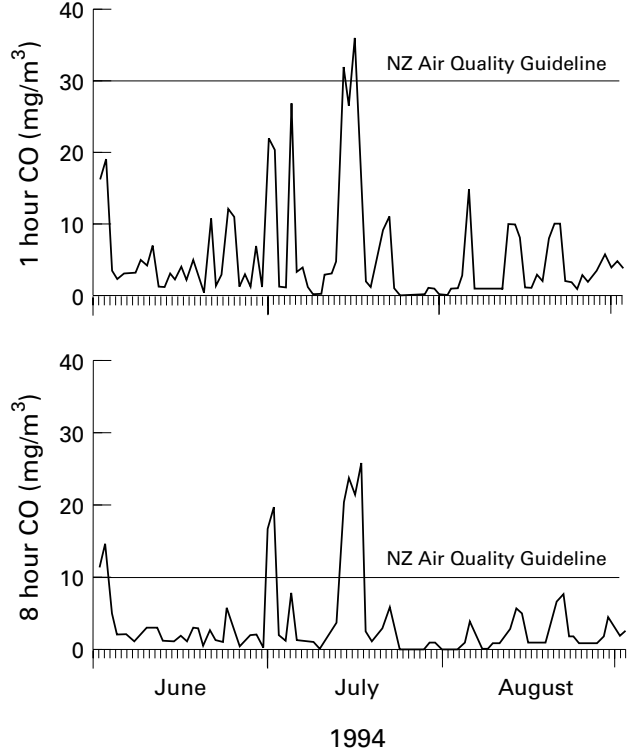

Figure 2 Mean daily data (one and eight hour means) for carbon monoxide during the study period.

Table 2 Effect of previous day's mean pollution levels on peak expiratory flow rate (PEFR)

\begin{tabular}{lcllll}
\hline Air pollutant & \multicolumn{2}{c}{ Morning PEFR } & & \multicolumn{2}{c}{ Evening PEFR } \\
\cline { 2 - 3 } & \% change & $95 \%$ CI & & \% change & 95\% CI \\
\hline $\mathrm{CO}$ & 0.06 & -0.24 to 0.36 & & 0.08 & -0.29 to 0.44 \\
$\mathrm{NO}_{2}$ & -0.44 & -0.92 to 0.04 & & 0.07 & -0.33 to 0.47 \\
$\mathrm{PM}_{10}$ & 0.05 & -0.35 to 0.44 & & -0.15 & -0.40 to 0.11 \\
$\mathrm{SO}_{2}$ & 0.05 & -0.15 to 0.26 & & -0.06 & -0.23 to 0.11 \\
\hline
\end{tabular}

The tabulated effects correspond to the estimated mean change in peak flow associated with an increase in the level of the pollutant equivalent to the interquartile range for the pollutant. The interquartile ranges were as follows: $\mathrm{CO}$ (carbon monoxide) $1.33 \mathrm{mg} / \mathrm{m}^{3}, \mathrm{NO}_{2}$ (nitrogen dioxide) $9.74 \mu \mathrm{g} / \mathrm{m}^{3}, \mathrm{PM}_{10}$ (particulate matter $<10 \mu \mathrm{m}$ in diameter) $35.04 \mu \mathrm{g} / \mathrm{m}^{3}, \mathrm{SO}_{2}$ (sulphur dioxide) $4.58 \mathrm{\mu g} / \mathrm{m}^{3}$. All estimates are adjusted for the effects of temperature, wind speed, and day of study as well as for the effects of the other pollutants listed.

Table 3 Effect of previous day's mean pollution levels on occurrence of night time chest symptoms and wheeze

\begin{tabular}{llllll}
\hline \multirow{2}{*}{ Air pollutant } & \multicolumn{2}{l}{ Chest symptoms } & & \multicolumn{2}{l}{ Wheeze } \\
\cline { 2 - 3 } & $R R$ & $95 \% C I$ & & $R R$ & $95 \% C I$ \\
\hline $\mathrm{CO}$ & 0.73 & 0.58 to 0.92 & & 0.95 & 0.08 to 1.14 \\
$\mathrm{NO}_{2}$ & 1.25 & 0.76 to 2.07 & & 1.18 & 0.85 to 1.65 \\
$\mathrm{PM}_{10}$ & 1.38 & 1.07 to 1.78 & & 0.97 & 0.75 to 1.26 \\
$\mathrm{SO}_{2}$ & 0.95 & 0.80 to 1.13 & & 0.99 & 0.78 to 1.26 \\
\hline
\end{tabular}

$\mathrm{RR}=$ relative risk

The tabulated effects correspond to the estimated relative risk for developing night time chest symptoms or wheeze associated with an increase in the level of the pollutant equivalent to the interquartile range for the pollutant. For interquartile ranges see footnote to table 2 . All estimates are adjusted for the effects of temperature, wind speed, and day of study as well as for the effects of the other pollutants listed.

Table 4 Effect of current day's mean pollution levels on day time nebuliser and reliever inhaler use

\begin{tabular}{llllll}
\hline \multirow{2}{*}{ Air pollutant } & \multicolumn{2}{l}{ Nebuliser use $(n=12)$} & & \multicolumn{2}{l}{ Inhaler use } \\
\cline { 2 - 3 } & $R R$ & $95 \% C I$ & & $R R$ & $95 \% C I$ \\
\hline $\mathrm{CO}$ & 0.95 & 0.74 to 1.22 & & 1.08 & 0.99 to 1.18 \\
$\mathrm{NO}_{2}$ & 1.44 & 0.91 to 2.26 & & 1.42 & 1.13 to 1.79 \\
$\mathrm{PM}_{10}$ & 0.71 & 0.42 to 1.18 & & 0.94 & 0.78 to 1.13 \\
$\mathrm{SO}_{2}$ & 1.00 & 0.78 to 1.28 & & 1.05 & 0.94 to 1.17 \\
\hline
\end{tabular}

$\mathrm{RR}=$ relative risk.

The tabulated effects correspond to the estimated relative risk for both nebuliser use or increased day time use of reliever medication (two or more puffs greater than median) associated with an increase in the level of the pollutant equivalent to the interquartile range for the pollutant. For interquartile ranges see footnote to table 2 . All estimates are adjusted for the effects of temperature, wind speed, and day of study as well as for the effects of the other pollutants listed. guidelines, high levels of $\mathrm{PM}_{10}$ and $\mathrm{CO}$ were recorded on several occasions. Mean 24 hour $\mathrm{NO}_{2}$ and $\mathrm{SO}_{2}$ levels were well within the guidelines. The mean 24 hour $\mathrm{PM}_{10}$ levels exceeded the guideline of $120 \mu \mathrm{g} / \mathrm{m}^{3}$ five times. The guidelines for $\mathrm{CO}$ are defined as one hour and eight hour standards. The eight hour standard of $10 \mathrm{mg} / \mathrm{m}^{3}$ was exceeded four times and the one hour standard of $30 \mathrm{mg} / \mathrm{m}^{3}$ was exceeded on two occasions.

\section{LUNG FUNCTION}

There was no significant association between any individual pollutant and either morning or evening PEFR (table 2). The strongest effect observed was that of the previous day's $\mathrm{NO}_{2}$ concentration on morning PEFR. After adjusting for other pollutants, temperature and wind speed, the estimated average percentage fall in PEFR corresponding to an increase in $\mathrm{NO}_{2}$ equivalent to the interquartile range of $9.74 \mu \mathrm{g} / \mathrm{m}^{3}$ was $0.44 \%$.

\section{SYMPTOMS}

The largest effect seen was an increase in night time chest symptoms in association with a raised $\mathrm{PM}_{10}$ concentration. There was a relative risk of 1.38 (95\% CI 1.07 to 1.78$)$ of experiencing increased night time chest symptoms in association with a mean increase in the $\mathrm{PM}_{10}$ level equivalent to the interquartile range of $35.04 \mu \mathrm{g} / \mathrm{m}^{3} . \mathrm{NO}_{2}$ had no effect on wheeze or night time chest symptoms. There was an apparent inverse association between $\mathrm{CO}$ and night time chest symptoms (table 3 ).

There was a weak association between increased $\mathrm{SO}_{2}$ levels and eye irritation. The relative risk was 1.17 (95\% CI 0.99 to 1.38 ) of experiencing eye irritation in association with a mean increase in $\mathrm{SO}_{2}$ level equivalent to the interquartile range of $4.58 \mu \mathrm{g} / \mathrm{m}^{3}$.

\section{MEDICATION USE}

Table 4 shows the effect of the current day's pollution levels on day time use of reliever medication. Raised $\mathrm{NO}_{2}$ levels were associated with both increased inhaler and nebuliser use. There was a relative risk of 1.44 (95\% CI 0.91 to 2.26) of requiring increased nebuliser use and a relative risk of 1.42 (95\% CI 1.13 to 1.79) of requiring increased reliever inhaler (two or more puffs greater than the median) in association with an increase in the level of $\mathrm{NO}_{2}$ equivalent to the interquartile range of $9.74 \mu \mathrm{g} / \mathrm{m}^{3}$.

Twenty four hour lag analysis showed a relative risk of 2.81 (95\% CI 1.81 to 4.39 ) of requiring increased nebuliser use in association with an increase in $\mathrm{NO}_{2}$ equivalent to the interquartile range. There was little evidence of an association between the current day's mean pollution level and risk of increased night time medication use. The strongest effect was for $\mathrm{PM}_{10}$ where the relative risk was $1.15(95 \%$ CI 0.91 to 1.46) for an increase in $\mathrm{PM}_{10}$ level equivalent to the interquartile range. 
There was no evidence of any association between air pollution concentrations and corticosteroid or antibiotic use.

\section{Discussion}

The main findings of this study are that, despite the relatively low levels of pollution recorded, a number of adverse health effects were documented. Increased $\mathrm{PM}_{10}$ levels were associated with increased night time chest symptoms, high levels of $\mathrm{NO}_{2}$ were associated with increased use of reliever inhaler and high levels of $\mathrm{SO}_{2}$ were associated with eye irritation. Interestingly, there was no evidence of any effect of air pollution on PEFR which may reflect the relative insensitivity of this variable in subjects with COPD, or possibly PEFR changes were partially masked by additional doses of bronchodilator.

Our findings are suggestive of a link between $\mathrm{NO}_{2}$ and symptomatic deterioration requiring additional reliever inhaler. Although the observed association between $\mathrm{NO}_{2}$ levels and night time chest symptoms and day time wheeze were not statistically significant, the effects of $\mathrm{NO}_{2}$ are coherent and overall suggest a real effect. Although the association between $\mathrm{PM}_{10}$ levels and respiratory symptoms is well established, ${ }^{73-19}$ the published literature regarding the respiratory effects of $\mathrm{NO}_{2}$ remains incomplete. ${ }^{619-23}$ Higgins et $a l^{9}$ found no association between $\mathrm{NO}_{2}$ and peak flow rate, respiratory symptoms, or medication use after adjustment for $\mathrm{SO}_{2}$. Recent data suggest that $\mathrm{NO}_{2}$ has the potential to aggravate airway reactivity, possibly through an oxidant effect. ${ }^{21}$

We did not find any effect of $\mathrm{SO}_{2}$ on chest symptoms or PEFR, although a raised $\mathrm{SO}_{2}$ concentration was associated with eye irritation. Raised particulate $\left(\mathrm{PM}_{10}\right)$ concentrations were associated with increased night time chest symptoms. Higgins $e t a l^{9}$ did not measure $\mathrm{PM}_{10}$ levels in their study but speculate as to whether their observation that raised levels of $\mathrm{SO}_{2}$ were associated with increased wheezing might reflect an effect of particulates which tend to covary with $\mathrm{SO}_{2}$.

We did not measure ozone levels during our study as the CRC believes that mean winter temperatures are too low to sustain ozone production. Nevertheless, future studies of this sort should include ozone measurement.

We are not able to provide any plausible explanation for the apparent protective effect of $\mathrm{CO}$ on the occurrence of night time chest symptoms. Given the large number of statistical tests performed, it is possible that this finding has occurred by chance.

Our small study population was self-selected and the magnitude of the significant effects seen was generally small. Thus, the results cannot be generalised to either the population as a whole or to all those with COPD. Nevertheless, it is clear that even within guideline levels of air pollution adverse health effects can be demonstrated in people with COPD. These findings emphasise the need for additional longer term studies in susceptible populations and may indicate a need for review of the air quality guidelines.

\section{Addendum}

Since this paper was written the Canterbury Regional Council has established a new national standard for $\mathrm{PM}_{10}$ of $50 \mu \mathrm{g} / \mathrm{m}^{3}$.

The authors acknowledge the Ministry of Health for permission to use their air pollution and meteorological data. $\mathrm{Dr} C$ Frampton provided additional statistical advice.

1 Canterbury Regional Council. Let's clear the air: issues and options for air quality management in Canterbury and back ground information. Report 93(35), December 1993.

2 Schwartz J, Dockery DW. Particulate air pollution and daily mortality in Steubenville, Ohio. Am $\mathcal{F}$ Epidemiol 1992;135: $12-9$

3 Schwartz J, Dockery DW. Increased mortality in Philadelphia associated with daily air pollution concentrations. Am Rev Respir Dis 1992;145:600-4.

4 Dockery DW, Pope CA III, Xiping Xu, et al. An association between air pollution and mortality in six US cities. $N$ Engl f Med 1993;329:1753-9.

5 Ponka A. Asthma and low level air pollution in Helsinki. Arch Environ Health 1991;46:262-70.

6 Rossi OVJ, Kinnula VL, Tienari J, Huhti E. Association of severe asthma attacks with weather, pollen and air pollutants. Thorax 1993;48:244-8.

7 Schwartz J, Slater D, Larson TV, Pierson WE, Koenig JQ Particulate air pollution and hospital emergency room
visits for asthma in Seattle. Am Rev Respir Dis 1993;147: visits for

8 Ware JH, Ferris BG, Dockery DW, et al. Effects of ambient sulphur oxides and suspended particles on respiratory health of preadolescent children. Am Rev Respir Dis 1986; 133:834-42.

9 Higgins BG, Francis HC, Yates CJ, Warburton CJ, Fletcher AM, Reid JA, et al. Effects of air pollution on symptoms and peak expiratory flow measurements in subjects with obstructive airways disease. Thorax 1995;50:149-55.

10 American Thoracic Society. Chronic bronchitis, asthma, and pulmonary emphysema: a statement by the Committee on Diagnostic Standards for Nontuberculous Respiratory Diseases. Am Rev Respir Dis 1962;85:762-8.

11 Schouter EG, Dekker JM, Kok FJ, et al. Risk ratio and rate ratio estimation in case-cohort designs: hypertension and ratio estimation in case-cohort designs: hypertension a
cardiovascular mortality. Statist Med 1993;12:1733-45.

12 Gourieroux C, Monfort A, Trognou A. Pseudo-maximum likelihood methods: theory. Econometrica 1984;52:681700.

13 Schwartz J. Short term fluctuations in air pollution and hospital admissions of the elderly for respiratory disease. Thorax 1995;50:531-8.

14 Braun-Fahrlander C, Ackermann-Liebrich U, Schwartz J, et al. Air pollution and respiratory symptoms in preschoo children. Am Rev Respir Dis 1992;145:42-7.

15 Pope CA III, Kanner RE. Acute effects of $\mathrm{PM}_{10}$ pollution on pulmonary function of smokers with mild to moderate chronic obstructive pulmonary disease. Am Rev Respir Dis 1993;147:1336-40.

16 Seaton A, MacNee W, Donaldson K, Godden D. Particulate air pollution and acute health effects. Lancet 1995;345: $176-8$.

17 Pope CA III, Thun MJ, Namboodiri MM, et al. Particulate air pollution as a predictor of mortality in a prospective study of US adults. Am $\mathcal{F}$ Respir Crit Care Med 1995;151: 669-74.

18 Pope CA III, Dockery DW, Spengler JD, Raizenne ME. Respiratory health and $\mathrm{PM}_{10}$ pollution: a daily time series Respiratory health and PM $_{10}$ pollution: a daily
analysis. Am Rev Respir Dis 1991;144:668-74.

19 Tattersfield A. Air pollution: brown skies research. Thorax 1996;51:13-22.

20 Devalia JL, Rusznak C, Herdman MJ, Trigg CJ, Tarraf H, Davies RJ. Effect of nitrogen dioxide and sulphur dioxide on airway response of mild asthmatic patients to allergen inhalation. Lancet 1994;344:1668-71.

21 Anto JM, Sunyer J. Nitrogen dioxide and allergic asthma starting to clarify an obscure association. Lancet 1985 345:402-3.

22 Jarvis D, Chinn S, Luczynska C, Burney P. Association of respiratory symptoms and lung function in young adults with use of domestic gas appliances. Lancet 1996;347: 426-31.

23 Devalia JL, Campbell AM, Sapsford RJ, et al. Effect of nitrogen dioxide on synthesis of inflammatory cytokines expressed by human bronchial epithelial cells in vitro. Am f Respir Cell Mol Biol 1993;9:271-8. 